\title{
El efecto de diferentes virus sobre el rendimiento potencial de la papa en la sierra central del Perú
}

\author{
U.C. Scheidegger**, L. Bertschinger**, K.Luther**, \\ O. Pinillos***, J. Muñoz ${ }^{* * * *}$, A. Hidalgo***
}

\section{RESUMEN}

Durante dos ciclos de cultivo, en 1985-86 y 1988-89, se investigaron los efectos de los principales virus sobre el rendimiento de papa en la sierra central del Perú a 3,200 msnm. Se utilizaron los cultivares mejorados Yungay y Mariva (Solanum tuberosum ssp. andigena $\mathrm{x}$ Solanum tuberosum spp. tuberosum) determinándose que los virus PLRV y PVY transmitidos por los áfidos, reducen hasta la mitad el rendimiento de una población originada en tubérculos-semilla sanos, en tanto que los virus transmitidos por contacto y sus combinaciones entre ellos, solamente ocasionaron una reducción significativa del rendimiento en el caso de poblaciones de baja densidad de siembra. Mientras más largos los estolones del cultivar, la densidad debía ser más baja para que se manifestara el efecto de los virus. En este trabajo se discuten la utilidad de los métodos empleados y su eficiencia para detectar los mecanismos de transmisión de los virus.

Palabras claves Adicionales: $\quad$ PVX, PVS, APMV, APLV, PVY, PLRV, densidades de siembra, efecto compensatorio.

Aceptado para publicación: agosto 29, 1996

* Este trabajo ha sido financiado por el proyecto " Producción e Investigación en Papa para Mejorar la Productividad de la Papa en el Perú" (Convenio INIAA-CIPCOTESU)

** Ph.D., Especialista en Producción de Semilla; Ing. Agr., Virólogo; Ing. Agr., Viróloga; Centro Internacional de la Papa (CIP). Apartado 1558, Lima, Perú.

*** Ing. Agr. Agrónoma; Viróloga; Ing. Agr., Director del Programa de Investigaciones en Papa (PIPA/INIAA); PIPA Estación Experimental Agropecuaria Santa Ana, Huancayo, INIAA, Ministerio de Agricultura, Lima, Perú.

**** B.C.; Facultad de Agronomía, Universidad Nacional del Centro del Perú, Huancayo, Perú. 


\section{The Effect of Different Viruses on the Potential Yield of Potato in the Central Highlands of Peru}

\section{SUMMARY}

During two potato seasons, 1985-86 and 1988-89 in the central Peruvian highlands $(3,200 \mathrm{~m})$, the effects of the main potato viruses on the crop yield were investigated. The improved potato cultivars, Yungay and Mariva, (Solanum tuberosum ssp. andigena x Solanum tuberosum spp. tuberosum) were used. Results indicated that the aphid transmitted viruses, PLRV and PVY, cause up to 50\% of yield reduction of a crop originated from healthy seed -tubers. Virus transmitted by contact, and their combinations, only caused significant yield reduction at low planting densities. In cultivars with longer stolons, plant density should be lower for virus effect to become evident. In this study the usefulness of different methods and their efficiency for detecting virus transmission mechanisms are discussed.

Additional index words: PVX, PVS, APMV, APLV, PVY, PLRV, planting densities, compensatory effect

Se conoce que los virus pueden afectar seriamente la producción de la papa, reduciendo el rendimiento hasta en $70 \%$, dependiendo del virus, del cultivar de papa y del medio ambiente en que se desarrolla el cultivo. En la región andina, existen pocos estudios acerca del efecto de los virus en el rendimiento de la papa $(6,12)$.

El Programa Nacional de Investigaciones en Papa (PIPA) del Instituto Nacional de Investigación Agraria (INIA), tiene como objetivo mejorar los bajos rendimientos que con una media de 8 t/ha (5) se registran en el Perú, por medio de la producción y uso de semillas de alta calidad, basándose en los buenos resultados obtenidos en otros países para resolver este problema (4).

En el Perú se consideran como importantes los siguientes virus: PVX, PVS, APMV, APLV, PVY y PLRV. Por lo tanto los investigadores del PIPA las han estudiado en detalle, incidiendo en el efecto que tienen en la productividad de la papa, bajo las condiciones agroecológicas del país $(1,14)$. 
En esta publicación se presentan los resultados de los experimentos realizados a 3,250 m para determinar las pérdidas por efecto de los virus. Las condiciones experimentales pueden considerarse representativas de las principales zonas productoras de papa en la sierra central del Perú.

\section{MATERIALES Y MÉTODOS}

El tubérculo de papa utilizado para sembrar se llama tubérculo-semilla o simplemente semilla. Se considera a priori tubérculos-semilla de alta calidad aquellos con menos de $4 \%$ de tubérculos infectados con virus. Igualmente se denomina "Semilla del agricultor" o "semilla común" a los tubérculos-semilla que han sido producidos por agricultores según sus métodos tradicionales. La "semilla del agricultor" está generalmente infectada con diferentes virus y es utilizada en la zona investigada por la gran mayoría de agricultores para la siembra de sus campos. Las semillas de alta calidad y las del agricultor utilizadas en los diferentes estudios, tenían al momento de la siembra, la misma edad fisiológica y procedían de la misma zona agroecológica.

Se utilizaron dos métodos para determinar el efecto de las enfermedades viróticas sobre el rendimiento potencial. El método denominado CPI, basado en la Cosecha de Plantas Individuales y el método llamado de Parcelas Enteras en el que se utilizan parcelas sembradas enteramente con semilla de determinada calidad (sana o enferma).

Con el método CPI se comparó el rendimiento de una planta infectada (A) con el de una planta sana adyacente (B) seguida a continuación de una planta sana (C) situada entre plantas sanas. La planta sana (B) al lado de una enferma (A) tiene a menudo un rendimiento superior a la planta (C) por causa del efecto compensatorio. Las secuencias de plantas en un surco para este tipo de experimento pueden ser: "sanaenferma-sana-sana-sana". Estas secuencias pueden buscarse en campos de agricultores y también pueden sembrarse con este propósito en experimentos. El diseño utilizado fue de bloques completamente randomizados al azar (BCR), con repeticiones.

En experimentos preliminares se encontró que las condiciones en los campos de agricultores eran heterogéneas (distancia de siembra, fallas, mezclas varietales), lo que dificultó la detección de efectos significativos. Aquí se reportan solamente resultados de experimentos conducidos en la Estación Experimental Agropecuaria de Santa Ana, Huancayo ubicada a $3250 \mathrm{msnm}$, en el Valle del Mantaro.

Otro problema del método CPI es que a causa de los estolones largos de los cultivares sembrados en la sierra no se logra cosechar exactamente los tubérculos de las plantas A, B, y C. En consecuencia se obtienen resultados que subestiman la merma y el efecto compensatorio. Por estas razones sólo se Utilizan parcelas enteras sembradas con semilla infectada con un determinado virus.

Utilización del método CPI: Se sembraron en la campaña 1985/86 
dos experimentos con los cultivares mejorados ampliamente utilizados; Yungay y Mariva; (ambas Solanum tuberosum spp. andigena $\mathrm{x}$ Solanum tuberosum spp.), para estudiar la interacción entre manejo agronómico y la calidad de la semilla. Se utilizó un diseño en parcelas divididas con el arreglo factorial de 2 × 2 $\mathrm{x} 3$, con 4 repeticiones que consistieron en los siguientes factores $\mathrm{y}$ niveles:

1) Semilla: Semilla básica (2\% de los tubérculos con infección virótica) y semilla de un agricultor infectada con virus (94\% de virus para Yungay y 76\% para Mariva).

2) Densidad de Siembra: $1 \mathrm{~m}$ entre surcos y 0,33 y 0,50 m entre plantas respectivamente (0,33 y $0,50 \mathrm{~m} 2$ /plantas respectivamente).

3) Fertilización: 60 - 60 - 60:120 - 120 - 120 y 180-180-180 kg/ha de N- $\mathrm{P}_{2} \mathrm{O}_{5}-$ $\mathrm{K}_{2} \mathrm{O}$.

Los niveles experimentales para fertilización y densidad cubren gran parte de la amplia gama empleada por los agricultores.

En las parcelas de estos experimentos se aplicó el método CPI, usando como plantas enfermas las que presentaron "síntomas viróticos fuertes" (rugosidad, mosaicos, etc). Se desconocían los virus particulares causantes de estos síntomas, pero representan los virus (PVX,PVS,APMV; 1) o sus combinaciones importantes, en una semilla fuertemente infectada de la región.

Estudios con virus determinados

Utilizando el método CPI: En 1985/86 se sembró un campo con la variedad Yungay, cultivar mejorado de mayor área sembrada en estos años en el Valle. Las plantas enfermas provinieron de sembrar tubérculos-semilla con infecciones secundarias, determinadas en brotes con ELISA. La distancia entre plantas fue 0,4 m y $1 \mathrm{~m}$ entre surcos. La fertilización fue de 135-150-120 kg/ha de $\mathrm{N}-\mathrm{P}_{2} \mathrm{O}_{5}-\mathrm{K}_{2} \mathrm{O}$. Se escogieron los virus y combinaciones de virus según los casos más frecuentemente encontrados en el Valle del Mantaro (1).

Utilizando el método de parcelas enteras: A fines de noviembre de 1986 en la EEA Santa Ana se sembraron parcelas enteras con tubérculos del cultivar Yungay, infectados con diferentes virus. Los cuatro tratamientos fueron: tubérculos-semilla de alta calidad (control); tubérculos infectados con PVX; con PVX combinado con PVS y con PVX combinado con APMV. Los tubérculos provenían de un experimento realizado en la campaña 1985/86 en la misma EEA y fueron analizados mediante ELISA en brotes. Se utilizó el diseño de bloques completos randomizados (BCR) con 4 repeticiones; cada parcela constituida de 5 surcos de 23 plantas cada una. La distancia entre surcos fue de $1 \mathrm{~m}$ y entre plantas $0,4 \mathrm{~m}\left(0,4 \mathrm{~m}^{2} /\right.$ planta). El nivel de fertilización fue 180-180-180 kg/ha de $\mathrm{N}-\mathrm{P}_{2} \mathrm{O}_{5}-\mathrm{K}_{2} \mathrm{O}$. En estas parcelas se realizó un análisis de crecimiento, determinando parámetros de crecimiento de plantas cosechadas en diferentes momentos de la campaña. Se cosecharon los tres surcos centrales de las parcelas, 
variando el número de plantas de acuerdo a las densidades $(0,4$ y 0.8 $\mathrm{m}$ entre plantas en surcos distanciados a $1 \mathrm{~m}$ ). Se registro el peso de la totalidad de los tubérculos producidos en la parcela del tratamiento respectivo. En la tabla 1 se presentan los resultados de esta cosecha.

Tabla 1. Rendimiento comparativo (kg/planta) de plantas sanas y con síntomas viróticos en el follaje. Variedad Mariva, campañas 1985/86.

\begin{tabular}{ccccc}
\hline & & \multicolumn{3}{c}{ Tratamiento } \\
\cline { 3 - 5 } Fertilización & Número & & & \\
\cline { 3 - 5 } & repet. & $\mathrm{A}$ & $\mathrm{B}$ & $\mathrm{C}$ \\
\hline $60-60-60$ & 9 & $1.14(75) \mathrm{a}$ & $1.44(95) \mathrm{b}$ & $1.51(100) \mathrm{b}$ \\
$120-120-120$ & 13 & $1.40(73) \mathrm{a}$ & $1.75(91) \mathrm{b}$ & $1.93(100) \mathrm{b}$ \\
$180-180-180$ & 12 & $1.17(61) \mathrm{a}$ & $2.01(104) \mathrm{b}$ & $1.93(100) \mathrm{b}$
\end{tabular}

Tratamiento A: plantas con síntomas típicamente viróticos (rugosidad, mosaicos)

Tratamiento B: planta sin síntomas, adyacente a la planta con síntomas

Tratamiento C: planta sana entre plantas sanas (control)

Distancia entre surcos: $100 \mathrm{~cm}$; entre planta $50 \mathrm{~cm}$

Números entre paréntesis indican el porcentaje con respecto al tratamiento C. Promedios seguidos por la misma letra dentro de una línea no son significativamente diferentes en la prueba de DMS $(\mathrm{P}=0.05)$.

a) $\mathrm{kg} / \mathrm{ha} \mathrm{N}-\mathrm{P}_{2} \mathrm{O}_{5}-\mathrm{K}_{2} \mathrm{O}$.

En la campaña 1988/89 se sembró con el cultivar Yungay un experimento similar al anterior pero sin análisis de crecimiento, para cuantificar el efecto de los virus en el rendimiento final. Se incluyeron 2 tratamientos: semilla de alta calidad (control) y semilla infectada con la combinación de los virus PLRV y APMV. Los tubérculos utilizados provenían de plantas infectadas de la campaña anterior, analizadas por ELISA. Se sembraron parcelas con 6 surcos y 12 plantas por surco en un BCR con 4 repeticiones. La distancia entre surcos fue $1 \mathrm{~m}$ y entre plantas $0,33 \mathrm{~m}\left(0,33 \mathrm{~m}^{2} /\right.$ planta). Se cosecharon 24 plantas en los 4 surcos centrales. Se registró el peso de tubérculos de diferentes tamaños (consumo: $>100$ g, semilla: 50-100 g, pequeños: $<50$ g) y además los dañados por insectos y otras causas y los podridos. El nivel de fertilización fue de 180-180-180 kg/ha, de N$\mathrm{P}_{2} \mathrm{O}_{5}-\mathrm{K}_{2} \mathrm{O}$.

\section{Análisis serológico por ELISA}

El extracto de cortes se analizó con el método de ELISA descrito por Clark y Adams (3), con pequeñas modificaciones descritas por Gugerli (7), que facilitan la ejecución y precisión de la prueba. Se utilizaron anticuerpos monoclonales para la detección de PLVR (Bioreba AG, Suiza; dil: 1:1000) y Anticuerpos policlonales para PVY (IgG: 1,5 ug/ml; Conjugado: 2585 mU enzima/0,645 ug IgG/ml). 
Para el análisis de varianza se utilizaron la prueba de F y de LSD (2). Los valores porcentuales se transformaron antes del análisis por arcoseno o raíz cuadrada (8).

\section{RESULTADOS Y DISCUSION}

Estudios con semilla del agricultor

Utilizando el método CPI: Con el cultivar Mariva y una baja densidad de siembra $\left(0,5 \mathrm{~m}^{2} /\right.$ planta $)$ se detectó una reducción significativa del rendimiento de plantas con síntomas viróticos, comparado con el rendimiento de plantas sin síntomas. La merma en producción osciló entre 25 y 39\% para semilla de acuerdo al nivel de fertilización (Tabla 1). Este resultado coincide con aquellos obtenidos por la comparación de la cosecha completa de las parcelas respectivas, en las cuales se ubicaron las plantas escogidas para el método CPI (10). Con el cultivar Yungay no se encontraron diferencias significativas con el método CPI entre los rendimientos de plantas individuales procedentes de semilla de distinta calidad (10). Estos resultados se explican porque en investigaciones y observaciones posteriores se detectó que la identificación de una infección virótica por sintomatología visual en el follaje era fácil en el cultivar Mariva. A1 contrario, ésto no fue así en otros cultivares, por ejemplo Yungay, porque sólo un menor porcentaje de plantas demostró síntomas en este cultivar. Con este cultivar se observaron también síntomas, calificados como viróticos, que no eran causados por virus pero sí por factores ambientales. Este efecto se registró bajo condiciones de sierra (11 y Bertschinger, observaciones personales). Por lo tanto es posible que en los experimentos presentados aquí algunas plantas del cultivar Yungay, calificadas como viróticas por sintomatología, no eran realmente infectadas. Otra explicación para los resultados obtenidos son los estolones largos de los cultivares mejorados más comunes en el Perú, especialmente aquellos del cultivar Yungay, lo que hace probable, que con el método CPI se cosecharon tubérculos de la planta adyacente en la posición de la planta con síntomas. Esto hace difícil la detección de efectos significativos con esta metodología, sobre todo si las diferencias son pequeñas y los estolones del cultivar son especialmente largos.

\section{Estudios con virus determinados}

Utilizando el método CPI: La infección secundaria con PLRV y también aquella con PVY en combinación con PVX redujeron el rendimiento significativamente (reducción de 56 y 29\% respectivamente, Tabla 2). Estos virus se reportaron poco presentes en cultivares mejorados en la sierra peruana (1). Ninguna reducción del rendimiento pudo ser atribuida a PVS, PVX, APMV, APLV y combinaciones entre ellos (Tabla 2). Esto significa que los virus transmitidos por contacto, que son los más distribuidos en los cultivares mejorados (1), no causaron una merma significativa en Yungay, que era el cultivar mejorado más ampliamente sembrado en 
estos años. Es posible que estos resultados no significativos se explican en parte por el efecto causado por los estolones largos del cultivar Yungay, descrito bajo el párrafo anterior. Significa que el método CPI subestima la reducción del rendimiento por efecto de virus y que no parece apropiado para investigar el efecto de una infección virótica o un efecto compensatorio con los cultivares mejorados y peruanos bajo condiciones de sierra. Para la subestimación de la disminución del rendimiento por el método CPI a causa de estolones especialmente largos se obtuvo evidencia en secuencias, donde la planta adyacente a la infectada no emergió y que demostraron un efecto más pronunciado del virus que en caso de las secuencias completas (Scheidegger, comunicación personal).

Utilizando el método de parcelas enteras: No se detectaron diferencias significativas entre los rendimientos de los diferentes tratamientos para las plantas con una densidad de $0,4 \mathrm{~m}^{2} /$ planta (9 plantas centrales). Por otro lado, para las plantas con una densidad de $0,8 \mathrm{~m}^{2} /$ planta, en la cosecha se mostraron diferencias significativas entre semilla sana e infectada (Tabla 3 ). Se supone que solamente las plantas sanas pudieron beneficiarse del aumento de espacio de 0,4 a $0,8 \mathrm{~m}^{2} /$ planta. Una planta infectada dio el mismo rendimiento en las dos densidades (Tabla 3). Significa que una infección secundaria con PVX y también aquella con PVS o APMV en combinación con PVX solamente reducen el rendimiento en densidades muy bajas (menos de $0,4 \mathrm{~m}^{2} /$ planta).

La reducción del rendimiento causada por la infección con PLRV en combinación con APMV era 49\% (Tabla 4). La semilla infectada produjo significativamente menos rendimiento con tubérculos del tamaño semilla (50-100 g) y pequeño $(<50 \mathrm{~g})$. La mayor parte del rendimiento de la semilla de alta calidad $44 \%$ tenía tamaño semilla (50-100 g). El valor respectivo para la semilla infectada era significativamente menor (37,5\%; Tabla 4). Por lo tanto se concluyó que estos virus disminuyen sobre todo la producción de tubérculos de tamaño semilla. Vale enfatizar que en este experimento, la semilla infectada no produjo más tubérculos pequeños (<50 g) que la semilla de alta calidad. Especialistas en producción de semilla consideran que una semilla infectada produce más tubérculos pequeños (comunicaciones personales). Los resultados presentados aquí confirman las experiencias hechas en ensayos a nivel de finca donde la semilla básica produjo siempre una cosecha de distribución de tamaños uniformes y por lo tanto de mayor valor comercial (13).

Se requiere otra investigación para aclarar, si semillas infectadas a niveles de fertilización más bajos que aquel utilizado en este experimento producen una parte mayor de su rendimiento con tubérculos pequeños.

Los virus transmitidos por áfidos son poco prevalentes en la sierra peruana en cultivares mejorados (1). Por lo tanto, en la sierra, la probabilidad de que una semilla de un cultivar mejorado esté infectada al $100 \%$, como aquella que fue utilizada en el presente estudio, es baja. Sin embargo, este experimento permitió entender el efecto que 
pueden tener los virus sobre el rendimiento de papa bajo las condiciones agroecológicas de la Sierra Central.

Tabla 2. Efecto sobre el rendimiento de la variedad de papa Yungay por infecciones secundarías causadas por diferentes virus. $\mathrm{kg}$. por planta. Campaña 1985/86.

\begin{tabular}{|c|c|c|c|c|c|c|c|c|c|c|}
\hline \multirow[b]{2}{*}{$\begin{array}{c}\text { Virus } \\
\text { (combinación) }\end{array}$} & \multirow[b]{2}{*}{$\begin{array}{l}\text { Número } \\
\text { Repet. }\end{array}$} & \multicolumn{9}{|c|}{ Tratamiento } \\
\hline & & & A & & & B & & & $\mathrm{C}$ & \\
\hline PVS & 16 & 1.95 & (101) & $\mathrm{a}$ & 1.87 & (96) & $\mathrm{a}$ & 1.94 & (100) & $\mathrm{a}$ \\
\hline PVX & 99 & 2.24 & (104) & $\mathrm{a}$ & 2.16 & (100) & $\mathrm{a}$ & 2.16 & (100) & $\mathrm{a}$ \\
\hline PVX+PVS & 50 & 1.82 & (90) & $\mathrm{a}$ & 1.72 & (85) & $\mathrm{a}$ & 2.03 & (100) & $\mathrm{a}$ \\
\hline $\mathrm{PVX}+\mathrm{APMV}$ & 49 & 1.92 & (98) & $\mathrm{a}$ & 1.85 & (94) & $\mathrm{a}$ & 1.96 & (100) & $\mathrm{a}$ \\
\hline $\mathrm{PVX}+\mathrm{PVS}+$ & 22 & 1.43 & (86) & $\mathrm{a}$ & 1.39 & (83) & $\mathrm{a}$ & 1.66 & (100) & $\mathrm{a}$ \\
\hline PVX+APLV & 16 & 1.50 & (97) & $\mathrm{a}$ & 1.71 & (111) & $\mathrm{a}$ & 1.54 & (100) & $\mathrm{a}$ \\
\hline $\mathrm{PVX}+\mathrm{PVY}$ & 15 & 1.49 & (71) & $\mathrm{a}$ & 1.97 & $(94)$ & b & 2.09 & (100) & b \\
\hline PLRV & 8 & 1.19 & (44) & $\mathrm{a}$ & 1.77 & (66) & $\mathrm{a}$ & 2.69 & (100) & c \\
\hline
\end{tabular}

Tratamiento A: planta infectada

Tratamiento B: planta sana adyacente

Tratamiento C: planta sana entre plantas sanas (control)

Distancia entre surcos: $100 \mathrm{~cm}$; entre plantas: $40 \mathrm{~cm}$

Fertilización con 135-150-120 N- $\mathrm{P}_{2} \mathrm{O}_{5}-\mathrm{K}_{2} \mathrm{O}$ (kg/ha)

Los números en paréntesis indican el porcentaje de tratamiento C

Promedios seguidos por la misma letra dentro de una línea no son significativamente diferentes en la prueba de DMS ( $\mathrm{P}=0.05)$. 
Tabla 3. Efecto de diferentes virus sobre el rendimiento (kg/planta) de la variedad de papa Yungay en siembras de alta y baja densidad de plantas por ha. Campaña 1986/87.

\begin{tabular}{ccccc}
\hline $\begin{array}{c}\text { Cosecha } \\
\text { Tipo }^{\text {a) }}\end{array}$ & $\begin{array}{c}\text { Semilla } \\
\text { sana }\end{array}$ & PVX & PVX+PVS & PVX+APMV \\
\hline A & $1.72(100) \mathrm{a}$ & $1.71(94) \mathrm{a}$ & $1.62(94) \mathrm{a}$ & $1.61(93) \mathrm{a}$ \\
B & $2.28(100) \mathrm{b}$ & $1.61(71) \mathrm{b}$ & $1.69(74) \mathrm{b}$ & $1.51(66) \mathrm{b}$ \\
\hline
\end{tabular}

Distancia entre surcos: $100 \mathrm{~cm}$

a) A: Plantas centrales, $0.4 \mathrm{~m}$ de distancia entre plantas, 9 plantas por parcela.

B: Plantas restantes de cosechas secuenciales, $0.8 \mathrm{~m}$ de distancia entre plantas en la cosecha, 33 plantas por parcela.

Fertilización con 180-180-180 N- $\mathrm{P}_{2} \mathrm{O}_{5}-\mathrm{K}_{2} \mathrm{O}$ (kg/ha)

Los números en paréntesis indican el porcentaje del rendimiento de semilla sana.

Diseño de bloques completos randomizados al azar. Promedios seguidos por la misma letra no son significativamente diferentes en la prueba de DMS $(\mathrm{P}=0.05)$.

Tabla 4. Efecto del complejo de infecciones secundarias de APMV+PLRV sobre el rendimiento (tha) de la variedad de papa Yungay. Campaña 1988/ 89.

\begin{tabular}{|c|c|c|c|}
\hline Criterio & $\begin{array}{l}\text { Semilla de } \\
\text { calidad }^{\text {a) }}\end{array}$ & $\begin{array}{l}\text { Semilla } \\
\text { infectadab) }\end{array}$ & $\begin{array}{l}\text { Significancia } \\
\left.\text { Prueba F }{ }^{c}\right)\end{array}$ \\
\hline \multicolumn{4}{|l|}{ Rendimiento (t/ha) } \\
\hline Tubérculos consumo (>100g) & $11.5(100)$ & $6.4(54)$ & n.s. \\
\hline Tubérculos semilla (50-100g) & 23.5(100) & $10.2(43)$ & $* *$ \\
\hline Tubérculos pequeños (0-50 g) & $17.4(100)$ & $9.8(56)$ & $* *$ \\
\hline Tubérculos dañados & 1.1(100) & $0.6(52)$ & n.s. \\
\hline Rendimiento Total & $53.5(100)$ & $27.2(51)$ & $* *$ \\
\hline \multicolumn{4}{|l|}{ Porcentaje de cada categoría $^{\mathrm{d})}$} \\
\hline Tubérculos consumo & 20.3 & 23.1 & n.s. \\
\hline Tubérculos semilla & 44.0 & 37.5 & * \\
\hline Tubérculos pequeños & 32.8 & 36.6 & n.s. \\
\hline Tubérculos dañados & 1.5 & 1.6 & n.s \\
\hline
\end{tabular}

Distancia entre surcos: $100 \mathrm{~cm}$

Distancia entre plantas: $33 \mathrm{~cm}$ 
a) semilla con menos de 4\% de infección virótica.

b) semilla $100 \%$ infectada con APMV, combinado con PLRV.

c) $*$ : $\mathrm{p}<0.05, * *: \mathrm{P}<0.01$; transformación arcoseno para porcentajes.

d) Porcentajes son promedios retransformados de valores transformados por arcoseno.

Fertilización con 180-180-180 N-P $\left.\mathrm{O}_{5}-\mathrm{K}_{2} \mathrm{O}\right)(\mathrm{kg} / \mathrm{ha})$

Números entre paréntesis indican el porcentaje del rendimiento de semilla de calidad.

\section{REFERENCIAS BIBLIOGRÁFICAS}

1. Bertschinger, L., Scheidegger, U.C.,. Pinillos, O., Hidalgo A., Luther, K., 1990. La incidencia de virus de papa en cultivares nativos y mejorados en la sierra peruana. Revista Latinoamericana de Papa, mismo volumen y número.

2. Calzada Benza, J. 1970. Métodos estadísticos para la investigación. Ed Jurídica S.A. Lima, Perú.

3. Clark, M.R, Adams, A.N.. 1977. Characteristics of the microplate method of enzyme-linked inmunosorbent assay for the detection of plant viruses. Journal of General Virology. 34:475-483.

4. Ezeta, F.N., Scheidegger, U.C., 1985. Semilla básica: Un nuevo programa de producción y distribución para el Perú. CIP Circular 13(2): 1-5.

5. FAO. 1987. World crop and livestock statistics. 1948 -1985. Roma, Italia, p 159.

6. Guerrero Guerrero, O.; G. Martínez López. 1980. Evaluación de Pérdidas ocasionadas en el cultivar de papa Ica Puracé por los virus "potato virus Y" y "potato leafroll virus". Fitopatología Colombiana, 9:33.

7. Gugerli, P. 1986. Potato viruses. In: Bergmeyer (ed.). Methods of enzymatic analysis. Volume XI. Antigens and Antibodies 2. VCH Verlagsgesellschaft mbH, D-6940 Weinheim (Federal Republic of Germany). p. 430-446.

8. Gómez, K.A., Gómez A.A., 1976. Statical procedures for agricultural research with emphasis on rice. The International Rice Research Institute. Los Baños, Laguna, Philippines, p. 197. 
9. INIPA-CIP-COTESU. 1987. Proyecto "Manejo y producción de semilla para incrementar la productividad de la papa en el Perú". Informe anual 12.1986/ 87. Convenio INIPA-CIP-COTESU. Lima. p. 12.

10. ibid.p. 12-E.

11. ibid.p. 16-A.

12. Santos Rojas, J. 1985. Efecto del virus del enrollamiento de la hoja de la papa (PLRV) sobre el rendimiento total de cuatro variedades de papa en el sur de Chile, Simiente 55:38

13. Scheidegger, U.C., Cuyubamba, O. 1990. On-farm trials with potato seed in the Peruvian highlands In: D. Horton. Libro de edición. Título para averiguar.

14. Scheidegger, U.C., Luther K., 1987. Importance of potato viruses in the Peruvian highlands. Abstracs of papers presented at the 71st Annual Meeting. The Potato Association of America, St. Paul, Minn. Aug. 2-6, 1987. In: American Potato Journal, 64:456. 